\title{
TECNOLOGIAS DIGITAIS NA FORMAÇÃO INICIAL DOCENTE: ARTICULAÇõES E REFLEXÕES COM USO DE REDES SOCIAIS
}

\author{
DIGITAL TECHNOLOGIES IN INITICAL TEACHER TRAINING: \\ JOINTS AND REFLECTIONS WITH SOCIAL NETWORK USE

\section{TECNOLOGÍAS DIGITALES EN FORMACIÓN INICIAL DEL PROFESORADO: JUNTAS Y REFLEXIONES CON USO RED SOCIAL}

\section{Adriana Alves Novais Souza ${ }^{1}$ Henrique Nou Schneider ${ }^{2}$}

\begin{abstract}
RESUMO
Este trabalho discute o uso das Tecnologias Digitais de Informação e Comunicação na prática docente, no sentido de que estas estejam presentes desde a formação inicial, a partir de experiências que promovam a reflexão e práticas futuras. As discussões aqui apresentadas são frutos de uma dissertação de mestrado em Educação defendida na Universidade Federal de Sergipe, e tem por objetivo discutir a importância do uso das tecnologias na formação inicial docente como exercício da práxis, a fim de permitir aos futuros professores experiências que os motivem e os preparem para um uso efetivo. A pesquisa, de abordagem qualitativa, utilizou como método a pesquisa-formação no desenvolvimento de uma prática em que as tecnologias foram inseridas no cotidiano da disciplina de graduação, utilizando uma rede social como ambiente de aprendizagem. Os resultados evidenciam a urgência de metodologias e práticas que utilizem as tecnologias nas universidades, a fim de preparar os futuros docentes para as exigências da profissão na contemporaneidade.
\end{abstract}

PALAVRAS-CHAVE: Tecnologias Digitais de Informação e Comunicação. Formação Inicial Docente. Redes Sociais. Facebook.

\begin{abstract}
This paper discusses the use of Information and Communication Digital Technologies in teaching practice, in the sense that they are present from the initial training, from experiences that promote reflection and future practices. The discussions presented here are the result of a master's thesis in Education of the Federal University of Sergipe and aims to discuss the importance of use of technologies in initial teacher training as an exercise in practice in order to create opportunities for future experiments teachers that motivate and prepare them for effective use. The research, qualitative approach, used by the search-training method for developing a practice in which the technologies were inserted into the daily life of a discipline graduation, using a social network as a learning environment. The results show the urgency of methodologies and practices using technology in universities in order to prepare future teachers for the demands of the profession nowadays.
\end{abstract}

KEYWORDS: Digital Technologies of Information and Communication. Initial Teacher Training. Social networks. Facebook.

\section{RESUMEN}

\footnotetext{
${ }^{1}$ Mestra em Educação pela Universidade Federal de Sergipe, UFS, São Cristóvão, SE - Brasil. Professora do Colégio Estadual Senador Walter Franco, Estância, SE - Brasil. E-mail: dria.novais.souza@gmail.com.

${ }^{2}$ Doutor em Engenharia de Produção pela Universidade Federal de Santa Catarina, UFSC, Florianópolis, SC Brasil. Professor Associado do Departamento de Estatística e Informática da Universidade Federal de Sergipe, UFS, São Cristóvão, SE - Brasil. E-mail: hns @ terra.com.br.

Recebido em: 08/10/2015 - Aprovado em: 02/02/2016.
} 
En este trabajo se analiza el uso de la Información y la Comunicación Digital Technologies en la práctica docente, en el sentido de que están presentes desde la formación inicial, a partir de experiencias que promuevan la reflexión y prácticas futuras. Las discusiones que aquí se presentan son el resultado de una tesis de maestría en Educación de la Universidad Federal de Sergipe y tiene como objetivo discutir la importancia de la utilización eficaz de las tecnologías en la formación inicial del profesorado como un ejercicio de la práctica con el fin de crear oportunidades para los experimentos futuros profesores que motivan y prepararlos para su uso efectivo. La investigación, enfoque cualitativo, que utiliza el método de búsqueda de la formación para el desarrollo de una práctica en la que las tecnologías se insertaron en la vida cotidiana de una graduación de la disciplina, el uso de una red social como un ambiente de aprendizaje. Los resultados muestran la urgencia de las metodologías y prácticas que utilizan la tecnología en las universidades con el fin de preparar a los futuros docentes para las exigencias de la profesión hoy en día.

PALABRAS CLAVE: Tecnologías Digitales de la Información y la Comunicación. Formación Inicial Docente. Redes sociales. Facebook.

\section{INTRODUÇÃO}

Pesquisas que discutem a utilização das Tecnologias Digitais de Informação e Comunicação (TDIC) nas práticas docentes têm crescido na última década, como consequência das propostas de incentivo à sua inserção no ambiente escolar, tais como as direcionadas pelas Diretrizes Curriculares Nacionais da Educação Básica do Ministério da Educação e Cultura: "as tecnologias da informação e comunicação constituem uma parte de um contínuo desenvolvimento de tecnologias" [...] e, "como qualquer ferramenta, devem ser usadas e adaptadas para servir a fins educacionais [...] de forma a possibilitar que a interatividade virtual se desenvolva de modo mais intenso, inclusive na produção de linguagens" (BRASIL, 2013, p. 25).

Para tanto, têm sido criadas políticas públicas de informatização das escolas públicas, de inclusão digital (ProInfo, ProUca) e de incentivo à formação continuada de docentes (Mídias na Educação, Proinfo Integrado, entre outras), em parceria com as Secretarias Estaduais de Educação e, por meio destas, pelos Núcleos de Tecnologia na Educação (NTE)voltadas para o letramento digital e incentivo ao uso das mídias nas práticas docentes. Laboratórios de informática foram implantados, escolas receberam notebooks e tablets para seus alunos, programas de formação continuada foram oferecidos, mas, conforme pesquisas de Gatti, Barreto e André (2011), os resultados não têm sido satisfatórios.

Em seu levantamento acerca da formação do professor e das políticas a ela relacionadas, Gatti, Barreto e André (2011) evidenciaram que as formações oferecidas aos docentes são, em boa parte, negligenciadas e oferecidas de forma pontual e distante da realidade dos professores. Outrossim, não há qualquer evidência concreta de que o professor põe em prática o que foi visto nas formações continuadas oferecidas. Assim, todo o investimento em tecnologias na e para a escola torna-se inútil quando o professor não se sente seguro para utilizá-las de forma planejada e eficaz; quando se sente excluído do processo de tomada de decisões ou quando sua realidade não contempla o necessário para o seu uso efetivo. Sua utilização somente terá impacto nas escolas quando a preparação de bons professores for prioridade, pois "não há reforma educacional, não há proposta pedagógica 
sem professores, já que são os profissionais mais diretamente envolvidos com os processos e resultados da aprendizagem" (LIBÂNEO, 2011, p. 9).

Esse é o cerne do problema quando se trata de uso (ou, mais precisamente, do desuso) das tecnologias nas escolas, a despeito de todo o investimento público: a formação inicial e continuada do professor. Dentre tantas questões relacionadas a essa problemática, é fundamental refletir sobre as práticas, os métodos e as didáticas específicas para uso das TDIC nas licenciaturas. Isso porque não se pode exigir mudança no perfil dos profissionais da educação que saem das academias quando a formação que lhes é oferecida ainda ocorre sob moldes tradicionais; é preciso formá-los da mesma maneira que se espera que venham a atuar futuramente.

É nessa perspectiva, a da incorporação das TDIC no âmbito de um contexto de uso efetivo e conectado à prática, que se baseia este trabalho, oriundo dos resultados de uma pesquisa de mestrado em Educação realizado na Universidade Federal de Sergipe, cuja problemática girou em torno da necessidade de incorporação das TDIC nos processos de formação inicial docente, de maneira a dialogar com as principais necessidades de ensino e aprendizagem atuais, estabelecendo relação entre o ambiente de ensino presencial e o ambiente online, e oferecendo experiência concreta aos professores em formação.

A pesquisa foi desenvolvida nos moldes da pesquisa-formação, considerada como método profícuo à interseção teoria-prática-pesquisa. Desenvolveu-se uma prática de ensino com uma turma de graduação, tendo a plataforma de rede social Facebook como ambiente de aprendizagem para a realização de atividades relacionadas à disciplina. Explorou-se os recursos disponíveis, tais como bate-papo, fórum, vídeos, imagem, documentos, entre outros.

Dessa forma, os estudantes foram convidados a refletir acerca da prática vivenciada, destacando-se neste trabalho as experiências e percepções dos futuros docentes com o uso das TDIC em sua formação inicial, ao mesmo tempo em que se procurou evidenciar o exercício da práxis do professor-pesquisador na educação. A intenção é a de "aproximar pesquisa e educação como processos formativos que permitem o desenvolvimento dos sujeitos envolvidos (pesquisadores, professores, estudantes, entre outros"), como propõem Longarezi e Silva (2013, p. 217).

\section{IMBRICAMENTO SOCIEDADE-TECNOLOGIA-EDUCAÇÃO}

A utilização das TDIC nos espaços educativos compreende um processo amplo, relacionado às mudanças na sociedade, promovidas pela revolução tecnológica, e aos novos modelos culturais emergentes - e sobre como estes se refletem na educação.

Antes de mais nada, é importante explicitar que a concepção de educação aqui defendida é tomada em sentido amplo, compartilhada da visão holística de Forquin, que a compreende como "formação e socialização do indivíduo", pois "educação é sempre educação de alguém por alguém", o que "supõe sempre também a comunicação, a transmissão, a aquisição de alguma coisa: conhecimentos, competências, crenças, hábitos, 
valores" (FORQUIN, 1993, p. 10). Pensando na importância da escola sob tal aspecto, compreende-se o seu valor por ser o lócus estratégico para a produção do conhecimento, no qual as relações se constroem e são frutos de todo um processo histórico e social. Portanto, não se pode pensar a escola como uma instância estanque da sociedade e de suas dimensões culturais, políticas e econômicas.

Nas últimas décadas, as TDIC vêm modificando os estilos de vida das pessoas e ganhando cada vez mais espaço nas atividades cotidianas de crianças e jovens; em contrapartida, a escola tem perdido sua relevância na perspectiva do estudante atual, conforme estudos de Sibilia (2012). Baseando-se em pesquisas realizadas por uma instituição privada nacional, a autora considera que os altos índices de evasão escolar estão diretamente ligados ao desinteresse do aluno pela escola tradicional, e que, portanto, "manter o jovem na escola não é somente uma questão econômica", e enfatiza a necessidade de "criar e atender a demanda por educação", que garanta "a atratividade da escola" (2012, p. 65 e 66). A escola, compara a autora, é uma máquina cujas engrenagens devem estar bem ajustadas e lubrificadas; caso contrário, haverá perda da eficácia do ensino, processo que tem sido amplamente apontado nas discussões acerca da necessidade de reforma do currículo escolar a fim de atender ao perfil dos estudantes da geração atual.

Para Valente (1999), a escola deve se consolidar como o espaço no qual os acontecimentos e vivências do indivíduo seguem o mesmo ritmo em que ocorrem na sociedade, pois está imersa em suas relações sociais e estas, por sua vez, carregam aspectos de sua cultura familiar. Assim, explorar as TDIC no processo de ensino promove novas formas de acesso à informação e ao aprendizado, propiciando atividades que poderão ser desenvolvidas em um mesmo tempo, mas em espaços bem diversos, uma vez que em casa, no trabalho e em diversas outras circunstâncias o estudante utiliza-se dos recursos tecnológicos.

Porém, não se trata apenas de utilizar as tecnologias para a motivação da aprendizagem ou como tentativa de modernização das aulas, mas do fato de que elas fazem parte do modus vivendi da sociedade atual, como parte de um processo natural de evolução. Mudanças sociais implicam modificações no perfil dos alunos que chegam às escolas. Ao se refletir sobre como as novas tendências tecnológicas vêm afetando os diversos campos sociais (economia, política, meio-ambiente, etc.), percebe-se o quanto a educação ainda está "dissociada do mundo e da vida, o que vem exigindo significativas modificações no ensino, na aprendizagem e nos papéis até então desempenhados pelas instituições de ensino" (SANTOS; BLÁZQUEZ, 2006, p. 17).

É preciso então estabelecer uma relação com as TDIC em sala de aula que vá além das meras atividades focadas no meio em detrimento do processo de aprendizagem. Não basta levar os alunos para os laboratórios de informática ou propor a eles atividades estanques, que não exploram a sua interação com o outro e com todo o universo da cibercultura, como já ficou constatado por meio das pesquisas de Gatti, Barreto e André (2011), que tratam das barreiras para a implementação e eficácia de políticas públicas de inclusão na formação docente. 
Libâneo (2011) reitera esta assertiva, ao lembrar que toda prática deve pressupor objetivos, planejamento e intervenção para uma aprendizagem eficaz: "É preciso que aprendam a elaborar e a intervir no processo comunicacional que se realiza entre professores e alunos por meio de mídias" (LIBÂNEO, 2011, p. 71), num processo reflexivo acerca da própria ação docente (SCHÖN, 2000). A concepção de ensino sob essa ótica perpassa tanto a formação de professores como o próprio ensino, o currículo e a metodologia (LIBÂNEO, 2011).

Assim, é preciso cautela, por parte dos professores, para não incorrerem em práticas inconsistentes que, sob a bandeira da "modernidade" - e em busca de se libertarem das amarras da pedagogia tradicional, desconsideram as atividades empíricas que produzem pensamento reflexivo, gerando, em contrapartida, uma estimulação "que gira no vazio e se extingue no tédio" (SIBILIA, 2012, p. 91). O desafio proposto pela autora, e com o qual esta pesquisa dialoga, diz respeito ao estabelecimento de uma prática que vá além da estimulação tecnológica em sala de aula, mas que, diante do fluxo digital que invade os espaços escolares fomentados pela cibercultura, conceba "modos de se subjetivar, pensar e dialogar nessas condições" (SIBILIA, 2012, p. 92), enfatizando o processo de ensino e aprendizagem.

\section{POSSIBILIDADES E DESAFIOS NO USO DE REDES SOCIAIS NA EDUCAÇÃO}

A relevância de aliar as práticas de ensino às redes sociais se dá, principalmente, por sua capacidade de romper barreiras e reafirmar a aprendizagem que pode acontecer em espaços variados e a todo o tempo, e não exclusivamente na sala de aula, de acordo com o que defende Fava (2011), para quem a educação formal é a "grande responsável pela permanência de valores humanos imperecíveis" (SANTAELLA, 2013, p. 307), por meio da qual os saberes e habilidades se constroem progressivamente, dentro do processo de socialização.

Nesse sentido, o desafio dos sistemas educacionais reside em desenvolver estratégias que integrem as necessidades educacionais e os novos papéis que se revelam no cenário escolar, para estudantes e professores, principalmente para estes últimos, que necessitam da preparação e abertura necessárias para desenvolver estratégias de aprendizagem que se complementem, com segurança. $\mathrm{O}$ foco, destaca-se, deve estar na forma como professores e alunos ensinam e aprendem, de maneira formal ou não, e em como as redes sociais podem ser utilizadas na formação do professor.

De acordo com o entendimento de Santaella (2013), as redes sociais se constituem como o quarto grande marco da evolução dos computadores. O primeiro diz respeito aos semicondutores, o segundo ao computador pessoal e o terceiro corresponde à internet. A divisão estabelecida destaca o papel das redes sociais e a sua presença na agenda de preocupações do governo, empresas, mercado e também no âmbito da educação. 
Como a interação é protagonista nas relações sociais, ela se constitui como um fator de continuidade da rede por meio de seus atores, os quais promovem as conexões que sustentam as redes sociais (RECUERO, 2009). Assim, não há redes sem interação entre indivíduos, sem a presença do outro, quer nas formas tradicionais de comunicação face a face, quer pelas vias online: são fatores que se somam, a fim de incrementar as relações coletivas. Quanto mais o indivíduo interage, maior a dinâmica das redes sociais e mais perto se está do processo de inteligência coletiva, ubíqua, um produto das pessoas e suas competências, potencializado no ciberespaço. Neste ambiente, salienta Lévy (1996, p. 113), "cada um é potencialmente emissor e receptor num espaço qualitativamente diferenciado, não fixo, disposto pelos participantes, explorável”.

Porém, algumas considerações acerca da efemeridade das redes precisam ser feitas quando se considera o seu uso como ambiente de aprendizagem. Por serem espaços em constante modificação, cuja oferta de informação se dá constantemente (SANTAELLA, 2013), é preciso que haja a devida orientação, especialmente para estudantes ainda imaturos. Saber localizar conteúdos com capacidade seletiva e avaliativa, a fim de utilizá-los eficazmente, é um trabalho "refinado", afirma a autora (SANTAELLA, 2013, p. 305), por isso o suporte fornecido pela educação formal torna-se fundamental para que os processos de busca, seleção e avaliação possam ocorrer com segurança.

$\mathrm{Na}$ partir da dissertação de mestrado da qual parte este artigo, foi realizado um levantamento sobre o estado da arte do uso de redes sociais no país, e evidenciou-se o crescimento na última década de práticas docentes com uso das TDIC a partir de plataformas de redes sociais, principalmente o Facebook, devido ao seu grande fluxo de usuários em constante conexão, aos recursos de fácil utilização e às possibilidades de acesso geradas a partir de tecnologias móveis, muitas delas motivadas pela compreensão de que a sociedade mudou e pelo desejo de dialogar com as necessidades do alunado atual. Mattar (2013) fundamenta essa intenção: "As redes sociais são o habitat da geração que recebemos, hoje, em nossas escolas e universidades. Portanto, incorporar redes sociais à educação parece um passo instintivo para mantermos o contato com nossos alunos" (MATTAR, 2013, p. 15).

Promover e incentivar a motivação do aluno é o primeiro passo na busca de meios que possam fazer convergir as formas comunicacionais online com os processos de aprendizagem formal, mas não deve ser o único. Os professores podem e devem explorar esse potencial, uma vez que seus alunos já integram e dominam as redes sociais com desenvoltura. É possível não somente desenvolver projetos a curto e longo prazo, mas também utilizar a plataforma como ambiente de aprendizagem profissional docente, pois este pode criar e acompanhar páginas e grupos para a troca de ideias com outros professores, conhecendo e aperfeiçoando, assim, as suas propostas didáticas.

Ao mesmo tempo em que se verificam as possibilidades de uso efetivo, reflete-se também sobre os desafios colocados, pois não se trata exclusivamente do uso de recursos e plataformas disponíveis na web. A intenção deve ser a de desconstrução do contexto de uma educação nos moldes da era industrial, onde os alunos desempenham as mesmas funções, independentemente de seus perfis diversificados e de tempos e estilos de aprendizagem 
diferenciados, e no qual a figura docente permanece como a detentora do saber, que determina e utiliza recursos e estratégias de pouca relevância para o alunado. É importante propor metodologias nas quais as informações e conhecimentos disponíveis online sejam explorados em seu potencial, sempre considerando o contexto e adequando-o ao currículo.

Para compreender o papel que as TDIC podem desempenhar no contexto escolar, é preciso entender que tipo de formação deve ser transmitida, com o propósito de que os futuros docentes possam se tornar sujeitos da máquina e não meros objetos dela, extrapolando "as questões didáticas, os métodos de ensino, os conteúdos curriculares, a fim de encontrar caminhos mais adequados ao momento histórico que vivenciamos" (SANTOS; BLÁZQUEZ, 2006, p. 47).

\section{OS CAMINHOS DA PESQUISA}

A oportunidade de envolver o uso das TDIC na prática pedagógica surgiu mediante o desenvolvimento de uma pesquisa de mestrado, no exercício da docência de uma disciplina de graduação na Universidade Federal de Sergipe, ofertada pelo Departamento de Letras Vernáculas e de natureza optativa. A disciplina contou com 17 alunos de cursos diversos, tanto licenciandos oriundos da área educacional quanto de outras áreas acadêmicas, o que conferiu maior heterogeneidade que a normalmente encontrada em turmas de graduação.

Diante de tal perfil, questionou-se como motivar o diálogo e a interação entre esses alunos com interesses acadêmicos tão diversos, e sobre como promover encontros, debates e atividades em grupos, tendo em vista que alguns deles sequer estudavam nos mesmos turnos. Tais desafios constituíram os principais motivadores na intenção de criar um espaço de aprendizagem online, bem como da busca por uma rede social.

O desenvolvimento de uma atividade que estabelecesse uma maior aproximação do processo de ensino e aprendizagem com o universo comunicacional no qual o alunado está presente também foi fundamental no processo de planejamento da disciplina; por isso, buscou-se explorar o objeto da pesquisa (as redes sociais) por meior de um método que permitisse oferecer, no exercício da práxis, subsídios para o uso das TDIC na formação dos futuros docentes, compreendendo que a introdução destas precisa ir além da mera mudança tecnológica, como uma forma de convivência, participando dela e sendo seus principais agentes.

Nesse sentido,

A incorporação e utilização das novas tecnologias pelos professores de ensino superior necessitam da preparação dos profissionais que saibam utilizá-las, portanto é essencial que a ele seja oportunizada capacitação adequada. Nenhuma pessoa pode esperar fazer uso dos recursos se não se der ao trabalho de descobrir as possibilidades de sua utilização (SANTOS; BLÁZQUEZ, 2006, p. 16). 
Para isso, é preciso que o docente tenha muito clara as finalidades a que se propõe e que estabeleça objetivos que visem uma aprendizagem mediada pelas TDIC, cujo uso esteja centrado na reflexão crítica sobre os seus aspectos positivos e negativos.

Assim, a prática proposta partiu de dois propósitos: permitir a exploração dos recursos e possibilidades do uso das redes sociais em uma disciplina presencial (e, com isso, conhecer e explorar in loco o objeto da pesquisa), e propiciar aos graduandos, especialmente àqueles que atuam ou atuarão como docentes, a oportunidade de conhecer e adquirir experiências para suas práticas futuras.

Ramos, Linhares e Batista (2012) reforçam o exposto:

[...] a universidade assume um papel preponderante na formação de profissionais mais adequados ao mercado do trabalho e a educação de base passa a ser objeto de políticas que têm como preocupação desde o aumento no número de alunos na escola, a reformulação das políticas de acesso de jovens ao ensino superior e o incentivo à formação de pesquisadores por meio de programas de pós-graduação. Neste percurso, uma das hipóteses mais debatidas é a relação entre tecnologia e educação como fórmula para a melhoria da qualidade da educação e do desenvolvimento econômico de um país (RAMOS; LINHARES; BATISTA, 2012, p. 119).

Os autores reafirmam a ineficácia das políticas de implementação das TDIC quando estas se baseiam em orientações e intervenções pontuais por meio de pequenos cursos, enfatizando que a formação inicial docente, desenvolvida pelas universidades nas licenciaturas, precisa fazer relação com o contexto da sociedade da informação.

O método de abordagem da pesquisa foi o da pesquisa-formação que, de acordo com Longarezi e Silva (2008, p. 4.056), caracteriza-se como uma forma de se fazer ciência em que "o pesquisador sai da clausura de seu laboratório e vai atrás dos problemas do professorado, trabalhando com ele para a solução desses mesmos problemas de forma conjunta e cooperativa”. Trata-se de um modelo em que o pesquisador não é neutro, mas que reconhece as inúmeras relações envolvidas na escola enquanto local de realização da prática docente.

A delimitação por este método deu-se pela "implicação do pesquisador com o campo de pesquisa, construindo juntamente com os sujeitos envolvidos o conhecimento e o próprio método" (SANTOS, 2005, p. 92), quando o pesquisador é sujeito e objeto (NÓVOA, 2004), envolvido na reflexão acerca de sua práxis, o que implica no redimensionamento do papel docente e na formação de um professor crítico (LONGAREZI; SILVA, 2008), que articula pesquisa e ação, o que pressupõe mudanças não apenas das práticas, mas, principalmente, dos sujeitos em formação.

Os passos para o desenvolvimento da pesquisa-formação neste trabalho seguiram a orientação de Alvarado Prada (2005), no intuito de que a formação possa:

1) privilegiar situações a partir das quais os próprios educadores desenvolvessem e produzissem práticas e saberes novos, articulados com as teorias educacionais, mediante processos de investigação e colaboração em seus espaços de trabalho; 
2) ter como objeto de estudo as demandas da instituição, as necessidades e interesses formativos dos professores e as necessidades de aprendizagens dos estudantes (ALAVARADO PRADA, 2005, p. 2).

Foi proposto nas primeiras aulas a criação de um grupo no Facebook para postagem de atividades, discussões e contatos, o que permitiu desenvolver estratégias de acompanhamento e análise, como a observação participante, a qual, para Lüdke e André (1986, p. 28), envolve "não só a observação direta, mas todo um conjunto de técnicas metodológicas pressupondo um grande envolvimento do pesquisador na situação estudada".

A coleta de dados ocorreu a partir da observação participante, que aconteceu no ambiente do Facebook, com o intuito de promover subsídios para as discussões via fóruns e chats, permitindo a troca de informações, sugestões, experiências e propostas acerca das redes sociais e sua aplicabilidade no processo de ensino e aprendizagem. Outro instrumento de coleta proposto diz respeito a um questionário com perguntas abertas e fechadas, ao final da disciplina, a fim de coletar dados sobre a experiência do grupo diante da proposta, tais como: recursos utilizados, dificuldades enfrentadas, relações estabelecidas, apropriação da interface, perspectivas iniciais, entre outros. Destaca-se que os estudantes foram convidados a participar da pesquisa e concordaram com a exposição dos dados coletados, assinando o Termo de Consentimento Livre e Esclarecido. Foram atribuídos nomes fíctícios aos participantes e resguardados os sigilos de fotos e dados pessoais que permitissem a identificação, como se pode verificar na dissertação completa de que trata este artigo (SOUZA, 2015).

Sob tais moldes, a pesquisa apresenta, a partir de um relato minucioso da prática desenvolvida, as vivências, as interações, os fazeres e as reflexões, frutos da experiência de uso da plataforma de rede social Facebook como ambiente enriquecedor da disciplina ministrada, obtidos a partir das observações feitas pela professora-pesquisadora e pelos relatos dos estudantes, que refletiram sobre sua aprendizagem e seu processo de formação (SCHÖN, 2000). Segundo Longarezi e Silva (2008), a formação implica reflexão sobre a ação e as mudanças não apenas no profissional, mas na própria instituição escolar.

Dada a natureza da pesquisa, na área de formação de educadores, bem como de todo o processo que a norteia - de ordem da práxis pedagógica - buscou-se aprofundar, por meio de entrevista semiestruturada, questões relacionadas à formação docente e ao uso das TDIC, bem como à visão do licenciando e futuro professor sobre a associação entre os diversos recursos e conteúdos disponíveis na internet para fins pedagógicos. Para tanto, foram selecionados apenas os alunos das licenciaturas, num total de sete.

A proposta de adoção de um ambiente online que servisse de comunicação entre todos e, no qual fosse possível postar arquivos e explorar recursos diversos de apoio à aprendizagem em sala de aula, foi apresentada pela docente-pesquisadora na primeira aula, como um recurso auxiliar ao processo de ensino. A plataforma de uso escolhida foi o Facebook, dada a facilidade de seu uso, adesão da maioria dos estudantes à rede social (apenas um não possuía conta ativa), assim como algumas características que permitem seu 
uso como ambiente de aprendizagem, fundamentadas por autores como Mattar (2013), Pinto et al. (2012) e Bona (2012), entre outros.

O uso do Facebook como ambiente de aprendizagem buscou ir além de seu uso como um simples repositório de conteúdos que permite ao aluno se apropriar das informações e trocas de experiências, mas, como possibilidade de construir os caminhos de aprendizagens, por meio do desenvolvimento de práticas de leitura e análise de textos de diferentes tipologias e gêneros, que explora os recursos e ferramentas existentes no ambiente, tais como bate-papo, postagem de arquivos, organização de fóruns e enquetes e disponibilização de links e arquivos de mídias, como vídeo e músicas.

Foram estabelecidas atividades a serem realizadas na plataforma, sempre visando a exploração dos recursos disponíveis; além disso, no ambiente também eram postados os materiais utilizados na aula presencial, como slides em PowerPoint, vídeos e outros recursos midiáticos acessíveis aos alunos.

Todo o desenvolvimento da disciplina ocorreu concomitantemente ao uso do Facebook. Semanalmente foram propostas atividades no ambiente e postados os conteúdos das aulas, além de sugestões de textos, links e outros recursos de acordo com os conteúdos trabalhados. Também foram propostos fóruns e debates, textos colaborativos, entre outras atividades. A interação entre os estudantes ocorreu de maneira síncrona e assíncrona.

O questionário aplicado ao final da disciplina, bem como as observações feitas no grupo e em sala de aula, além dos dados coletados a partir de capturas de tela feitas de atividades e postagens no Facebook, disseram respeito a todos os graduandos participantes da disciplina, e foram fundamentais para a composição do perfil da turma. Ele serviu, também, como bússola para o levantamento de questões relevantes a serem exploradas na entrevista com os alunos licenciandos, foco deste artigo. Um relato mais minucioso sobre essa experiência pode ser verificado em Souza (2015), que trata da pesquisa de mestrado propriamente dita.

\section{USO DAS TDIC NA APRENDIZAGEM: O QUE DIZEM OS FUTUROS DOCENTES?}

Conforme Libâneo (2011), muitos dos conflitos existentes no exercício docente dizem respeito, atualmente, à relação entre educação e as TDIC.

Destacam-se:

\footnotetext{
- As necessidades do novo paradigma produtivo e a propalada universalização da escolarização básica;

- A multiplicidade dos meios de comunicação na sociedade informacional e a morte da escola;

- O uso da tecnologia informática na escola e a substituição da relação docente; - o impacto das NTIC na escola e a pouca receptividade dos educadores escolares em relação aos processos de inovação tecnológica (LIBÂNEO, 2011, p. 59).
} 
O foco tem recaído, principalmente, na figura do professor e nas novas competências necessárias à sua formação, inicial e em serviço, de acordo com a abordagem fundamentada em Shön (2000), Imbernón (2006) e Libâneo (2011). Outrossim, os autores também evidenciam que não bastam os investimentos voltados para a modernização tecnológica das escolas se não houver infraestrutura condizente e abertura ao diálogo com o docente, para que as mudanças necessárias sejam feitas de acordo com as especificidades de cada comunidade escolar. Nesse sentido, acredita-se na importância de direcionar este foco desde a formação inicial, oferecendo aos futuros docentes experiências reais de uso das TDIC e preparando-os ao mesmo tempo em que se discute criticamente esse uso.

Com base nisso, uma vez concluída a disciplina e a experiência empírica de que trata esta pesquisa e a fim de conhecer as percepções dos estudantes licenciandos acerca de sua própria formação, bem como acerca da prática pedagógica com uso das TDIC, especificamente com uso do Facebook e de como eles avaliam a proposta. Tal conduta está baseada no princípio da Pesquisa-formação que concebe o indivíduo como ser sujeito de ocorrências no contexto de pesquisa, implicando na compreensão acerca dos processos de produção de conhecimentos dos sujeitos diante de problemas por ele vivenciados em sua formação/ação docente.

Conforme Ramos, Linhares e Batista indicam, a universidade precisa pensar que, se a escola necessita de renovação, ela deve ocorrer em sua base, vale dizer, é na formação inicial docente que as primeiras mudanças precisam ser implementadas, já que "[...] a universidade assume um papel preponderante na formação de profissionais mais adequados ao mercado do trabalho" (RAMOS; LINHARES; BATISTA, 2012, p. 119).

Os autores discorrem sobre a ineficácia das políticas de implementação das TDIC quando estas se baseiam em orientações e intervenções pontuais por meio de pequenos cursos e, ainda, que a formação inicial docente, desenvolvida pelas universidades nas licenciaturas, precisa fazer relação com o contexto sociotécnico da sociedade da informação. Pensando em tais aspectos, buscou-se conhecer o que pensam os futuros docentes e alunos de licenciatura entrevistados em relação à preparação do professor para o uso das TDIC.

\footnotetext{
As TIC avançam rapidamente e a universidade, como as escolas de uma maneira geral, têm ficado bem atrás em relação às TIC [...]. A gente observa que muitas vezes o professor está ali no quadro [...] e o aluno no celular o tempo todo, mexendo no notebook. Então, acho que a universidade tem que abrir mais para o uso das TIC a favor dela mesma e também para alcançar e absorver mais do aluno. A universidade precisa mudar (ALFA).

Considero que ainda o ensino está muito tradicional, o professor ainda é visto como uma autoridade. Vejo um grande de desinteresse por parte do aluno, principalmente em determinadas disciplinas, matérias. Isso é bem complicado, porque é muito difícil organizar numa sala, praticamente a maioria ou todos os alunos utilizando as redes sociais, o WhatsApp, tudo é bem complicado (EPSILON).
}

Os estudantes relataram a distância entre as práticas de ensino em sala de aula e as novas formas comunicacionais dos estudantes da geração Y, cujo perfil está associado a uma maior capacidade de utilizar equipamentos de comunicação digitais de forma intensa, com 
rapidez e facilidade. Tais indivíduos crescem em meio a mudanças, o que requer aceleração na forma de agir e de absorver informações. Conforme o relato de Alfa, o que se tem são alunos "que não estão nem á'", sempre conectados em redes sociais e inseridos em um ensino tradicional no qual impera o uso exclusivo de recursos como quadro e giz, baseado em longas horas de estudos sem qualquer motivação para o aluno.

As novas exigências educacionais pedem, nas palavras de Libâneo, um professor "capaz de ajustar sua didática às novas realidades da sociedade, do conhecimento, do aluno, dos diversos universos culturais, dos meios de comunicação". Esse novo perfil docente precisa também contar não só com uma visão cultural geral mais ampliada, como também com "a capacidade de aprender a aprender, competência para saber agir na sala de aula, habilidades comunicativas, domínio da linguagem informacional, saber usar meios de comunicação e articular as aulas com as mídias e multimídias" (LIBÂNEO, 2011, p. 12).

Pensando nisso, questionou-se se os alunos entrevistados cursaram alguma disciplina que discutisse o uso das TDIC, ou se algum professor desenvolveu uma proposta nesse sentido, relatando a experiência. Dentre os relatos, consideram-se duas situações bem comuns em pesquisas com esse mesmo foco: "Não. Só a disciplina Português Instrumental, a maioria não... O máximo que usamos aqui é o Datashow e assim mesmo só alguns professores que usam” (ALFA).

Teve uma disciplina que foi Artes visuais e novas TIC, que envolvia não só o computador, mas também televisão, cinema, enfim... Foi uma matéria que eu peguei e que estava em fase de reformulação do curso, então teve muito problema, o professor chegou atrasado. Foi bem complicado (EPSILON).

O depoimento retrata bem as circunstâncias em que a universidade em análise tem introduzido disciplinas relacionadas ao uso das TDIC: em geral ofertadas como optativas e, portanto, à disposição entre tantas outras nas grades, além da ausência de professores para ministrá-la desde o início do período, o que normalmente provoca aligeiramento e práticas pouco efetivas. Outros estudantes relataram que não tiveram nenhuma disciplina assim, pois as que envolviam tecnologias eram optativas e não foram eleitas em suas grades de estudo.

É preocupante essa situação de ausência de experiências mais diretas do licenciando com as TDIC, pois de que forma o futuro docente poderá atender às demandas da nova geração, como determinam as Diretrizes da LDB 9394/96, “incluindo as novas linguagens e tecnologias, considerando os âmbitos do ensino e da gestão, de forma a promover a efetiva aprendizagem dos alunos" (BRASIL, 1999)? Como desenvolver uma competência que não foi explorada em sua formação?

Porém, entre os relatos dos licenciandos, um deles apresentou-se diferenciado, oriundo de um cursista de Letras Português-Inglês.

[...] no caso de português não foi assim um sucesso, agora na parte de inglês sim. Os professores disponibilizam de tudo, sempre tem debate em sala de aula dizendo como você deve reger uma boa aula de inglês, sempre disponibiliza bons materiais. 
Na metodologia, que eu peguei agora, foi fundamental porque o professor fala bem do que a gente deve aplicar em sala de aula (ÔMICRON).

Esse depoimento inspira a busca por maiores detalhes, já que o aluno evidencia que não se trata de uma disciplina isolada para o uso das TDIC, mas de uma metodologia empregada por professor do curso (limitado à língua estrangeira). O licenciando esclarece.

O professor sempre alerta para a gente fazer uma mesclagem (sic), não usar um só método. Então o método, como sou uma pessoa mais prática, eu sou mais pelos métodos que usem o aluno e não que o aluno só receba, porque só o aluno recebendo informação não vai para a frente, ele precisa pôr a mão na massa para que ele possa assimilar bem as informações. Em inglês minha formação está $100 \%$, não tenho nada a reclamar. O professor até agora tem usado muitos aplicativos, internet, que é fundamental (ÔMICRON).

O que Ômicron afirma também dialoga com o que Ramos, Linhares e Batista (2012) expõem acerca dos novos indicadores dos benefícios das TDIC na educação, em um manual publicado pela UNESCO em 2009, que trata da experiência.

[...] proveniente e construída a partir do conhecimento dos professores e habilidades, que deve ser bom o suficiente para utilizar as TIC para alcançar os objetivos educacionais. Refere-se não só a habilidades técnicas, mas também para o conhecimento pedagógico e conhecimento do objeto, bem como para a capacidade de ligar significativamente estes três elementos (RAMOS; LINHARES; BATISTA, 2012, p. 127).

O relato do licenciando fundamenta a relevância da formação docente estar voltada para a construção de competências avançadas, relacionadas com a produção e disseminação de conteúdos, com a comunicação em rede e inserção das TDIC no currículo, pois assim há um maior envolvimento por parte dos estudantes, e isso se refletirá na comunidade escolar, cujas práticas exitosas serão disseminadas e influenciarão novas experiências positivas no processo de aprendizagem.

Assim, o profissional reflexivo, na concepção de Shön (2000), precisa estar atento aos fenômenos que emergem culturalmente e ser capaz de propor novos modelos de ensino que, embora modernos em sua forma, se apresentem simples em sua proposta, compatíveis com os limites de seu ambiente de ação, ou seja, devem ser precisos em seus resultados.

Considerando o uso das redes sociais no processo de aprendizagem da disciplina, os alunos destacaram a colaboração e a conexão entre os conteúdos estudados em sala e os recursos online como um grande diferencial para fortalecer o processo de ensino e aprendizagem.

Geralmente, os trabalhos em grupo foram tranquilos. Dividíamos os assuntos, discutíamos alguma coisa. Geralmente a gente se organizava na biblioteca, num curto espaço de tempo. Mas na rede social mesmo é que a gente conversava mais. Houve divisão de trabalho, a gente discutia bastante o assunto, trocava informação (ÉPSILON).

Eu pude ter acesso ao que você fala, o que você fala eu também quero saber, porque às vezes isso influencia no que eu formular. Então isso é essencial, porque às vezes, no caso de uma prova, de uma atividade, o professor pega e só tem acesso para ele. 
A gente fica curioso em saber o que ele escreveu, a gente não tem acesso [...] (OMICRON).

Os alunos conseguiram estabelecer uma relação harmoniosa para a resolução de um objetivo comum: conciliar os horários entre os integrantes dos grupos e desenvolver uma boa apresentação, utilizando o espaço de aprendizagem para esse fim e estabelecendo as mesmas relações em equipe no ambiente online que poderiam ser desenvolvidas presencialmente. Isso porque o trabalho em equipe, conforme Schneider (2002, p. 56), "engaja seus membros em um espírito de cooperação, troca de informações, flexibilidade e realização, diferente daquele existente nos ambientes onde reina a competição e o individualismo".

Analisando a experiência com uso das redes sociais, especificamente o Facebook, os licenciandos apontaram como positivas as oportunidades de empreender discussões síncronas e assíncronas entre si e com a pesquisadora-docente; de propor e realizar atividades diversas; de acompanhar o processo de realização das tarefas e de participação dos alunos; de estabelecer comunicação mediante avisos e prazos; e de postar recursos sob diversos formatos (vídeo, imagem, texto), tudo dentro de um grupo fechado com diretrizes estabelecidas previamente, e com privacidade.

A ampliação do espaço de aprendizagem, citado pelos alunos da disciplina, foi o grande diferencial da proposta, permitindo dar continuidade às discussões promovidas em sala, além da opção de desenvolver suas atividades em horários condizentes com o tempo disponível. Os licenciandos, em sua maioria, ressaltaram o saber construído em conjunto, compartilhado, que promoveu maior cuidado com a produção e recepção do texto, como também a oportunidade de saber o que o outro diz, por que ele diz e as razões que fundamentam o seu pensamento.

Outro fator relevante foi o interesse e envolvimento nas atividades.

\footnotetext{
Acho que foi facilitado o aprendizado, não ficou aquela coisa carregada, só ali na sala de aula, todo mundo vai embora e acabou, não, a gente em casa pesquisava, estudava. Então, porque geralmente quando não fazemos uso das TIC a gente fica preso só na sala de aula, acabou aula, pronto. Com uso do face não, tanto nós estávamos na sala de aula conectado como em casa (ALFA).
}

A importância de motivar a participação dos estudantes e estimular seu posicionamento crítico foram atributos considerados positivos pelos discentes, reafirmando a relevante competência a ser desenvolvida nos estudantes e, principalmente, nos futuros docentes: o processo reflexivo.

Por fim, considera-se que uma boa proposta metodológica, aplicada a uma turma em processo de formação, somente será eficaz quando seus frutos puderem ser vistos, quer em mudanças de olhares e paradigmas pré-estabelecidos, quer em ações motivadas a partir dela. Nesse sentido, interessou à pesquisadora-docente saber em que medida a experiência os afetou para o desenvolvimento de práticas futuras mediadas pelo uso das TDIC. Por exemplo: "Eu gostei, por isso utilizei a ideia na monitoria, achei que foi válido, uma forma de interagir a mais não só com o professor mas também com os colegas" (EPSILON). 
Futuramente, pretendo, se puder, usar em meu estágio. [...] vamos ver as condições dos alunos, porque nem sempre todos têm as condições, nem todos têm computador, smartphone [...] pois eu acho que os alunos não têm esse acesso e no Facebook eu tenho essa chance [...]. Então, justamente essa experiência que eu levei da matéria que usou a rede social me pôs a pensar que a gente não deve só se limitar ao quadro e giz e nem ao papel na sala de aula (ÔMICRON).

A disciplina ajudou muito porque, sinceramente, eu não pensava em usar o Facebook da maneira que foi usada [...] a gente encontra muita coisa legal na internet, mas não tinha pensado em usar o face assim, para desenvolver atividades, pesquisas, opiniões, que eu achei bastante interessante (sic) (ALFA).

Procurou-se explorar, nos questionamentos, a perspectiva instrucional dos discentes, incorporando-as à análise a fim de conhecer seu olhar sobre a didática pedagógica e sua própria formação, ou seja, dar-lhes voz buscando conhecer as suas percepções e como avaliam as práticas pedagógicas. Com isso, buscou-se alcançar o que Santos e Blázquez (2006) apontam: quando o professor reflete sobre a sua prática com a intenção de promover uma aprendizagem autônoma, está dando voz ao sujeito em formação e, assim, restituindo ao professor a sua identidade perdida; já ao aluno a sua responsabilidade perdida e, à universidade, sua condição de lugar no qual a interação e a aprendizagem caminham juntas, com o entusiasmo e prazer de quem sai à busca do desconhecido.

A aquisição de conhecimentos por parte do professor é um processo complexo, adaptativo e experiencial [...]. E quanto maior a sua capacidade de adaptação mais facilmente ela será posta em prática em sala de aula ou na escola e será incorporada às práticas profissionais habituais. Um dos objetivos de toda formação válida deve ser o de poder ser experimentada e também proporcionar a oportunidade para desenvolver uma prática reflexiva competente (IMBERNÓN, 2006, p. 17).

Destaca-se, porém, que não será a atuação de uma única disciplina nem de um único professor que poderão resolver os grandes problemas de aprendizagem; é preciso haver uma atitude de abertura menos preconceituosa dos educadores, a fim de considerar que, com a ajuda da tecnologia, é possível melhorar o ensino-aprendizagem por meio da utilização da interdisciplinaridade e da enorme inteligência coletiva que temos em nossas escolas.

Porém, é lamentável concordar com Imbernón (2006) quando este diz que a formação inicial que os professores recebem normalmente não lhes prepara para aplicar uma nova metodologia, nem promove a construção de métodos teóricos na prática de sala de aula. Ora, se é na formação inicial que o docente precisa conhecer novos métodos de ensino, então não basta que uma ou duas disciplinas sejam as únicas responsáveis por isso; se o professor deve possuir domínio pedagógico, inclusive acerca das novas linguagens e tecnologias, não será por meio da oferta de uma disciplina optativa que essa lacuna será preenchida. Cada professor atuante na formação docente deve ser um exemplo para o licenciando, a partir de sua própria prática.

\section{CONSIDERAÇÕES FINAIS}


Ao refletir sobre o uso que a educação pode fazer das TDIC em seu benefício, o professor poderá oferecer aos alunos as experiências educacionais que serão necessárias para o seu exercício na sociedade moderna, preparando-os para os papéis que lhes serão exigidos.

Com tal intuito, a pesquisa aqui apresentada, fundamentada no método da pesquisaformação, buscou demonstrar como um ambiente virtual utilizado em concomitância à disciplina presencial em todo o curso e não apenas em uma atividade ou projetos isolados, pode ser profícuo para o processo de formação inicial docente.

Os resultados, baseados nos relatos dos licenciandos pesquisados, evidenciam a ampliação do espaço e do tempo de aprendizagem como o grande diferencial da proposta com uso de redes sociais, permitindo dar continuidade às discussões promovidas em sala e, ao aluno, a opção de desenvolver suas atividades em horários condizentes com seu tempo disponível. Nos depoimentos, os discentes refletiram sobre as práticas vivenciadas ao longo de sua educação básica e, principalmente, sobre a sua formação inicial, destacando a ausência de uso das tecnologias, de práticas mais dinâmicas e de metodologias eficientes, o que culmina em insegurança em relação aos desafios futuros.

Destaca-se na pesquisa a importância do intercâmbio entre a formação inicial e a formação continuada, de maneira que a constituição dos futuros professores se nutra das demandas da prática, um processo que o estágio curricular do licenciando pode ajudar a fortalecer; infelizmente não é muito comum essa dialética entre os problemas enfrentados pelos docentes em exercício e os formadores e licenciandos nas universidades. Este seria um passo fundamental para uma reelaboração nas práticas curriculares dos futuros docentes. Isso porque aquilo se espera do professor no exercício da prática precisa fazer parte do currículo de sua formação, e não apenas em disciplinas isoladas, que tratam de metodologias e práticas, mas nas propostas dos próprios formadores.

Isso implica, necessariamente, em formação docente inicial, continuada e em serviço, pois são as atualizações constantes que possibilitam ao professor repensar suas práticas e articular modificações em seu modelo mental da práxis. Nesse sentido, é fundamental que as instituições de nível superior invistam na discussão e na exploração, nos cursos de licenciatura, das diretrizes curriculares para a educação básica, a fim de promover a capacitação inicial daqueles que irão atuar nessa etapa do ensino.

Para tanto, há que se incorporar as TDIC em seu currículo, e que isso se reflita na prática do professor atuante nas licenciaturas, indo além da discussão teórica, pois o enriquecimento e a diversificação das práticas docentes são produtos da relação pessoal do professor com o uso das tecnologias. Ou seja: não basta tratar do uso, mas da exploração de técnicas, recursos e metodologias variadas de forma didática, de maneira que estas façam parte naturalmente da prática do professor, até porque saber utilizar o computador e outras mídias para fins pessoais não garante que estes meios sejam utilizados como instrumentos pedagógicos.

\section{REFERÊNCIAS}


ALVARADO PRADA, Luis Eduardo. Pesquisa coletiva como um caminho na formação de Professores. In: ENCONTRO DE PESQUISAS EM EDUCAÇÃO, 3. 2005, Uberaba, MG. Anais eletrônicos... Uberaba: UNIUBE, 2005, p. 626-637.

BONA, Aline Silva de. Espaço de aprendizagem digital da Matemática: o aprender a aprender por cooperação. 2012. 248 f. Tese (Doutorado em Informática na Educação) Centro Interdisciplinar de Novas Tecnologias na Educação, Universidade Federal do Rio Grande do Sul, Porto Alegre, RS, 2012. Disponível em: 〈http://goo.gl/ybRuXr >. Acesso em: 08 out. 2015.

BRASIL. Ministério de Educação e Cultura. Secretaria de Educação Básica. Diretrizes Curriculares Nacionais da Educação Básica. Brasília: MEC: SEB, 2013. 565 p. Disponível em: <http://goo.gl/1SwnYG >. Acesso em: 08 out. 2015.

BRASIL. Decreto n. 3276/99, de 06 de dezembro de 1999. Dispõe sobre a formação em nível superior de professores para atuar na educação básica, e dá outras providências. Disponível em: 〈http://goo.gl/lGyI6F>. Acesso em: 13 jul. 2014.

FAVA, Rui. Educação 3.0: como ensinar estudantes com culturas tão diferentes. 2. ed. Cuiabá: Carlini e Caniato Editorial, 2011.

FORQUIN, Jean-Claude. Escola e cultura: as bases sociais e epistemológicas do conhecimento escolar. Porto Alegre: Artes Médicas Sul, 1993.

GATTI, Bernadete Almeida; BARRETO, Elba Siqueira de Sá; ANDRÉ, Marli Eliza Dalmazo de Afonso. Políticas docentes no Brasil: um estado da arte. Brasília: UNESCO, 2011. 300 p. Disponível em: 〈http://goo.gl/GP7ZH >. Acesso em: 08 out. 2015.

IMBERNÓN, Francisco. Formação docente e profissional: formar-se para a mudança e a incerteza. 6. ed. São Paulo: Cortez, 2006.

LÉVY, Pierre. O que é o virtual? Tradução de Paulo Neves. São Paulo: Ed. 34, 1996.

LIBÂNEO, José Carlos. Adeus professor, adeus professora?: novas exigências educacionais e profissão docente. São Paulo: Cortez, 2011.

LONGAREZI, Andrea Maturano; SILVA, Jorge Luiz da. Pesquisa-formação: um olhar para sua constituição conceitual e política. Contrapontos, Itajaí, SC, vol. 13, n. 03, p. 214-225. set./dez. 2013. Disponível em: 〈http://goo.gl/snN8oJ〉. Acesso em: 08 out. 2015. ISSN 19847114.

LONGAREZI, Andrea Maturano; SILVA, Jorge Luiz da. Interface entre pesquisa e formação de professores: delimitando o conceito de pesquisa-formação. In: CONGRESSO NACIONAL DE EDUCAÇÃO - EDUCERE, 8., Curitiba, PR, 2008. Anais eletrônicos... Curitiba: Champagnat, 2008. Disponível em: 〈http://goo.gl/v6G30y >. Acesso em: 08 out. 2015.

LÜDKE, Menga; ANDRÉ, Marli Eliza Dalmazo de Afonso. Pesquisa em educação: abordagens qualitativas. São Paulo: EPU, 1986. 
MATTAR, João. Web 2.0 e redes sociais na educação. São Paulo: Artesanato Educacional, 2013.

NÓVOA, Antonio. Prefácio. In: JOSSO, Marie Cristina. Experiências de vida e formação. São Paulo: Cortez, 2004.

PINTO, Sérgio Crespo Coelho da Silva; SERRÃO, Tássia; BRAZ, Lucas M et al. Redes sociais: impactos, desafios e pesquisas no cenário educacional. In: SCHNEIDER, Henrique Nou; LACKS, Solange (Org.). Educação no século XXI: desafios e perspectivas. São Cristóvão: Editora UFS, 2012, p. 85-116.

RAMOS, Fernando; LINHARES, Ronaldo Nunes; BATISTA, J. TIC em educação: um contributo para definição do papel do professor. In: LINHARES, Ronaldo Nunes; FERREIRA, Simone de Lucena; VERSUTI, Andrea Cristina. (Org.). As redes sociais e seu impacto na cultura e na educação do século XXI. 2 ed. Fortaleza: Edições UFC, 2012, p. 113-148.

RECUERO, Raquel. Redes sociais na internet. Porto Alegre: Sulina, 2009.

SANTAELLA, Lucia. Comunicação ubíqua: repercussões na cultura e na educação. São Paulo: Paulus, 2013.

SANTAELLA, Lúcia. Culturas e artes do pós-humano: da cultura das mídias à cibercultura. São Paulo: Paulus, 2003.

SANTOS, Edméa Oliveira dos. Educação on line: cibercultura e pesquisa-formação na prática docente. 2005. 105 f. Tese (Doutorado em Educação) - Faculdade de Educação, Universidade Federal da Bahia, Salvador, BA, 2005. Disponível em: <https://goo.gl/Q3I5Ml>. Acesso em: 08 out. 2015.

SANTOS, Ivanilde Pereira dos; BLÁZQUEZ, Florentino. Incorporação das novas tecnologias no ensino superior. Goiânia: R\&F, 2005.

SCHNEIDER, Henrique Nou. Um ambiente ergonômico de ensino-aprendizagem informatizado. 2002. 163 f. Tese (Doutorado em Engenharia de Produção). Universidade Federal de Santa Catarina, Florianópolis, SC, 2002. Disponível em: <https://goo.gl/oYTEGD>. Acesso em: 08 out. 2015.

SCHÖN, Donald. Educando o profissional reflexivo: um novo design para o ensino e a aprendizagem. Tradução de Roberto Cataldo Costa. Porto Alegre: Artmed, 2000.

SIBILIA, Paula. Redes ou paredes: a escola em tempos de dispersão. Tradução de Vera Ribeiro. Rio de Janeiro: Contraponto, 2012

SOUZA, Adriana Alves Novais. O facebook como ambiente de aprendizagem: uma análise da práxis presencial mediada pelo conectivismo pedagógico. Dissertação (Mestrado em Educação) - Universidade Federal de Sergipe, São Cristóvão, SE, 2015. Disponível em: $\langle$ https://goo.gl/pqlffH $>$. Acesso em: 08 out. 2015. 
VALENTE, José Armando. Mudanças na sociedade, mudanças na educação: o fazer e o compreender. In: VALENTE, José Armando (Org.). O computador na sociedade do conhecimento. Campinas: UNICAMP:NIED, 1999.

VALENTE, José Armando. Computadores e conhecimento: repensando a educação. Campinas: UNICAMP:NIED, 1998.

\section{Como citar este documento:}

ALVES NOVAIS SOUZA, Adriana; NOU SCHNEIDER, Henrique. Tecnologias digitais na formação inicial docente: articulações e reflexões com uso de redes sociais. ETD - Educação Temática Digital, Campinas, SP, v. 18, n. 2, abr./jun. 2016. ISSN 1676-2592. Disponível em:

<http://periodicos.sbu.unicamp.br/ojs/index.php/etd/article/view/8640946>. Acesso em: 04 jul. 2016. doi:http://dx.doi.org/10.20396/etd.v18i2.8640946. 